\title{
THE DEVELOPMENT OF IMAGE PROCESSING METHOD ON THE AUTOMATIC READING SYSTEM OF THE GLASS THERMOMETER USING A DIGITAL CAMERA
}

\author{
Gianto $^{1}$, Vera Firmansyah ${ }^{2, *}$, Irwan Setiawan $^{1}$, Achsan Rifani ${ }^{1}$
}

${ }^{\text {I} P u s a t ~ P e n g e m b a n g a n ~ S u m b e r ~ D a y a ~ K e m e t r o l o g i a n . ~ J l . ~ D a e n g ~ M u h a m m a d ~ A r d i w i n a t a ~ k m . ~ 3,4, ~ C i h a n j u a n g, ~}$ Kec. Parongpong, Kabupaten Bandung Barat, Jawa Barat 40559, Indonesia

${ }^{2}$ Akademi Metrologi dan Instrumentasi, Jl. Daeng Muhammad Ardiwinata km. 3,4, Cihanjuang, Kec. Parongpong, Kabupaten Bandung Barat, Jawa Barat 40559, Indonesia

*Corresponding Author Email: vera.firmansyah@kemendag.go.id

Received: 22 August 2020

Revised: 2 December 2020

Accepted: 8 December 2020

Online: 28 April 2021

Published: 30 April 2021

SPEKTRA: Jurnal Fisika dan Aplikasinya

p-ISSN: 2541-3384

e-ISSN: 2541-3392

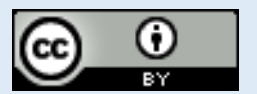

\begin{abstract}
The reading performance of an analog thermometer, Liquid in Glass Thermometer (LiGT), can be improved using a digital camera. The aim is to minimize the human error on the reading of LiGT and increase the accuracy of temperature measurement results. In order to achieve an accurate result, a robust image processing method is required in the measurement. In this work, the LiGT image generated using a digital camera is analyzed using the technique in HSV color space which consists of some image processing methods (e.g., thresholding, morphology filter). The type of LiGT used is the glass thermometer with the colored liquid. There are three main parts to this developed technique process, i.e., identifying the scale of LiGT to calculate the pixel per temperature unit value ( $p p t)$, segmentation of the liquid column, and calculate the temperature based on the $p p t$ value. Through simulation with a synthetic image, we demonstrate that the developed technique in this work has successfully read (measured) the temperature value of the LiGT (having a scale unit of $1^{\circ} \mathrm{C}$ ) with a measurement error of $0.04^{\circ} \mathrm{C}$. In the experimental results, we also report the developed technique performed on a real image of LiGT.
\end{abstract}

Keywords: LiGT, image processing, automated reading, temperature measurement 


\section{INTRODUCTION}

Glass thermometer/Liquid in Glass Thermometer (LiGT) is an analog temperature measuring instrument, which works based on the principle of the thermometric properties of the liquid column in the glass rod whose volume (the liquid column height) is proportional to the temperature value [1,2]. This type of temperature measuring instrument is one of the earliest forms of the thermometer, whose measurement range capabilities can reach the range between $-170^{\circ} \mathrm{C}$ and $330^{\circ} \mathrm{C}$ [3]. Currently, LiGT is still widely used, including in the fields of industry, health, and research laboratories. The Glass thermometer is easy to use. In terms of reading, it can be performed with the naked eye without requiring other auxiliary equipment. LiGT material is also made of glass, which is inert that it does not react to chemicals. In addition, the price of LiGT is relatively inexpensive, but still has good long-term stability at the same level of uncertainty [4].

Because the glass thermometer is an analog instrument, its reading is very simple visually, which can be performed with the naked eye or with the aid of a magnifying glass [5]. In terms of construction, LiGT does not have a communication interface with a computer, so that the reading can only be done manually. It is not possible to directly read the temperature measurement of LiGT automatically. The choice of the reading method is one of the most influential contributions to the LiGT calibration performance.

In metrology activities, the calibration of measuring instruments, including LiGT, has a significant role in maintaining the traceability of temperature measurements (traceability). Based on several literature sources, it is known that in addition to repeatability, a significant contribution of the uncertainty sources in the LiGT calibration is the scale division and the method of reading the scale of the LiGT [4,5]. The results of reading LiGT with the naked eye can be different from each other, depending on the ability of the calibration technician (subjective). The observation results of some technicians in reading the LiGT scale can reach up to $1 / 2,1 / 3$, or $1 / 4$ of a scale division. In order to increase readability, the magnification devices, such as a magnifier, can be used to allow interpolation up to smaller-scale divisions $[4,6,7,8]$.

Several factors, such as the technician's ability, the parallax error, and the fatigue on reading, can influence the uncertainty of the reading of the scale on LiGT. This certainly affects the accuracy and the precision of temperature measurement results. In order to minimize the possibility of reading errors, in this study, a vision system for reading the LiGT analog measuring instrument is developed. The aim is to improve the performance of temperature calibration in terms of simplification of measuring instrument readings and to increase the objectivity of the LiGT reading.

\section{VISION SYSTEM OF TEMPERATURE READING ON LiGT}

\subsection{DESIGN OF VISION SYSTEM}

The vision system includes digital image processing technology generated from a digital camera using a computer, which is then processed to obtain specific information $[9,10]$. Since the nature of the LiGT temperature reading is visual, the automation method of reading the 
LiGT scale can be performed using a digital camera, as shown in FIGURE 1. In FIGURE 1, it can be shown that when the temperature measurement using the LiGT was taking place, the LiGT image data were acquired using a digital camera. Then, it is needed an image processing and analysis of the image generated by the digital camera to calculate the temperature using a computer. In this study, the Matlab program was used to process the data.

The performance of the developed vision system depends on the optical capabilities of the digital camera and the design of the image acquisition system. The optimal design of the vision system prototype can make it easier to develop the image processing method required for the LiGT scale reading vision system. Meanwhile, the image processing method relies heavily on the performance of the segmentation process in identifying the scale line and liquid column in the glass rod.

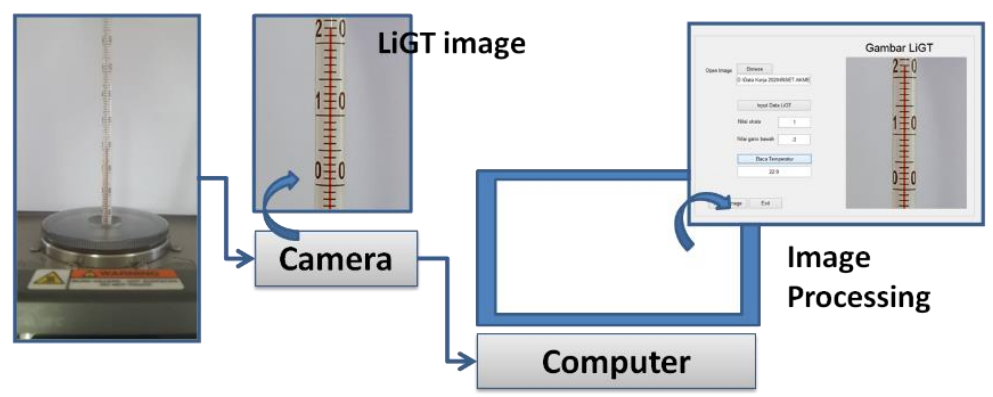

FIGURE 1. The vision system design of automatically temperature reading on LiGT.

\subsection{Image Processing and Analysis of LiGT Scale Reading}

In order to obtain precise and accurate results, it requires a robust image processing method in this measurement system. There are three main processes in the developed method, i.e., scale line and liquid column segmentation, identifying the LiGT scale to calculate pixels per temperature unit value (pixels per temperature - ppt), and calculating temperature based on the ppt value. In the image processing process in the developed method, the LiGT image is processed in the HSV (hue saturation value) color space technique for segmentation purposes for identifying the scale line and liquid column in a glass rod $[11,12]$.

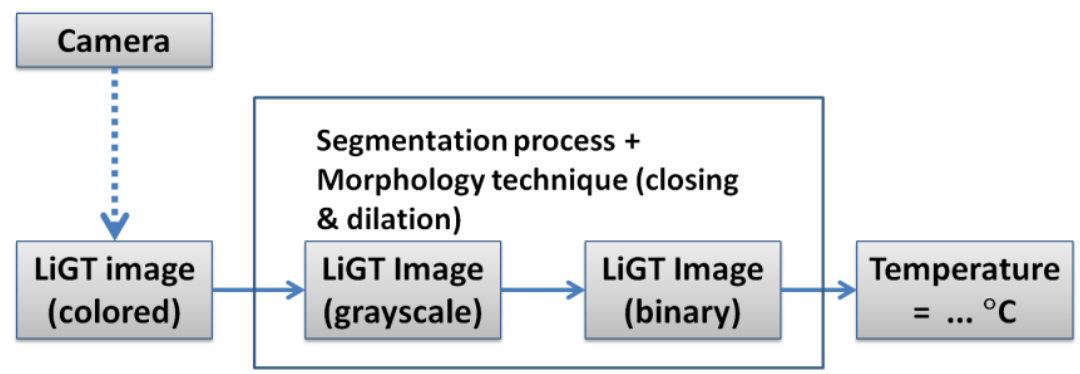

FIGURE 2. Image Processing Of Ligt Image

In the case of the LiGT temperature reading, it must been identifyed the position of the column height against the scale line on the LiGT. The segmentation process of the LiGT image, as 
shown in FIGURE 2, is carried out to make it easier to separate the object (scale line and liquid column on the glass rod) from the background. The segmentation process begins with converting the image format from a color image to a grayscale image, then followed by converting to be a binary image (black and white). In this developed image processing method, the morphological techniques, i.e. closing and dilation, will also be used to improve the quality of segmentation results, both in grayscale and binary images [13,14]. After the image segmentation in identifying the position of the liquid column height to the scale line has been performed, then the LiGT temperature is calculated based on the ppt value as the used standard.

\section{RESULTS OF SIMULATION/EXPERIMENTS AND DISCUSSION}

\subsection{SIMULATION RESULT}

As an initial step to test the performance of the developed image processing method, as described in section 2.2, a simulation is carried out using a synthetic LiGT image (FIGURE 3). By using the naked eye, the temperature value of the LiGT synthetic image can be read in the range of $22^{\circ} \mathrm{C}$.

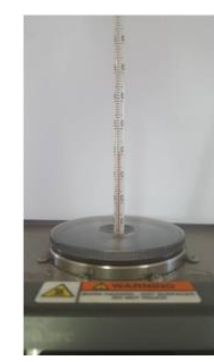

Real image of LiGT

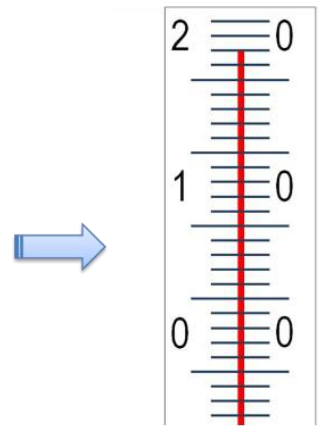

Synthetic image of LiGT

FIGURE 3. The simulation of automatic reading on LiGT synthetic image.

FIGURE 4 shows the main steps in the image processing method for reading LiGT. The conversion of FIGURE 4(a) to FIGURE 4(b) is the initial segmentation process from a color image to a grayscale image. Based on the results of the segmentation in FIGURE 4(b), it appears that the liquid column line segmentation (vertical) is discontinuous due to the presence of transverse (horizontal) scale lines. The morphological (closing) technique is a solution to resolve this problem to obtain a better segmentation image, as shown in FIGURE 4(c). The morphological (closing) technique is a technique in image processing, which serves to combine objects that are close together. Furthermore, to detect the edges of the liquid column and scale line, the binarization process is carried out by converting the grayscale image to a binary image (black and white), as shown in FIGURE 4(d). In the final process, the morphological (dilation) technique, which functions to enlarge the object segment, is required to overcome the thin column/scale line generated from the segmentation results, which can make it difficult in image analysis for temperature calculations. 


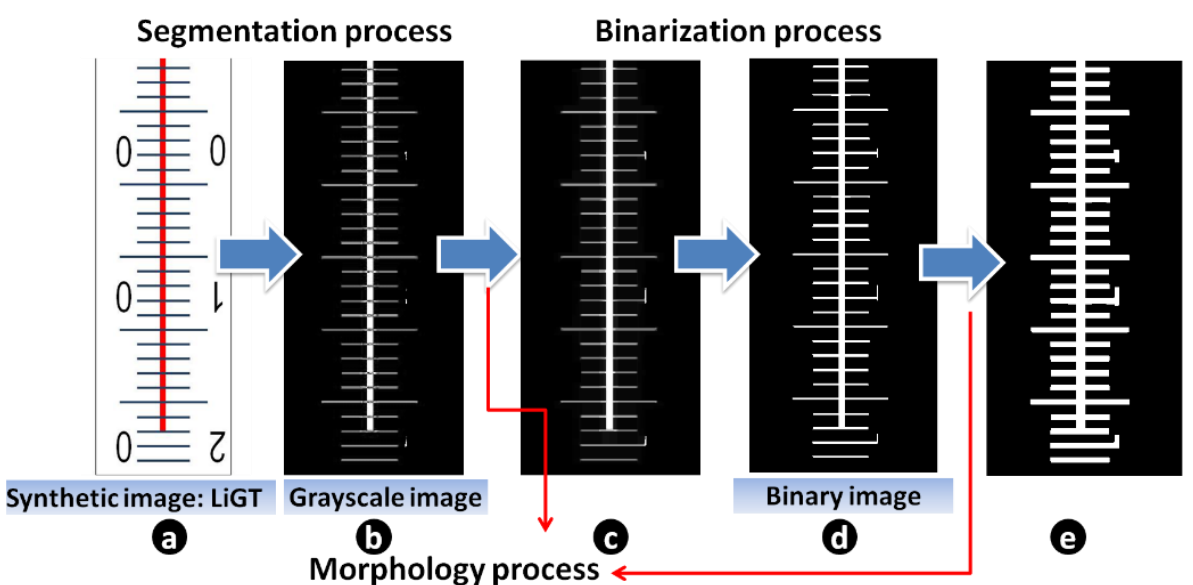

FIGURE 4. LiGT Synthetic Image Processing

After the step of the segmentation process, the image analysis for temperature calculations is carried out by identifying the position of the liquid column and the scale line, as shown in FIGURE 5. FIGURE 5 shown that the developed method successfully identifies the liquid column (blue) and the scale lines (red). By using the value of the lower scale line $=-3^{\circ} \mathrm{C}$ and the scale division $=1^{\circ} \mathrm{C}$, pixel per temperature scale (ppt) can be calculated, and the LiGT temperature reading can be determined according to the following equation.

Temperature of LiGT $=$ value of the lower scale line $+($ number of scale lines $\times$ scale division $)+\ldots$

+ ppt $\times($ remaining column pixels - scale line width correction $)$

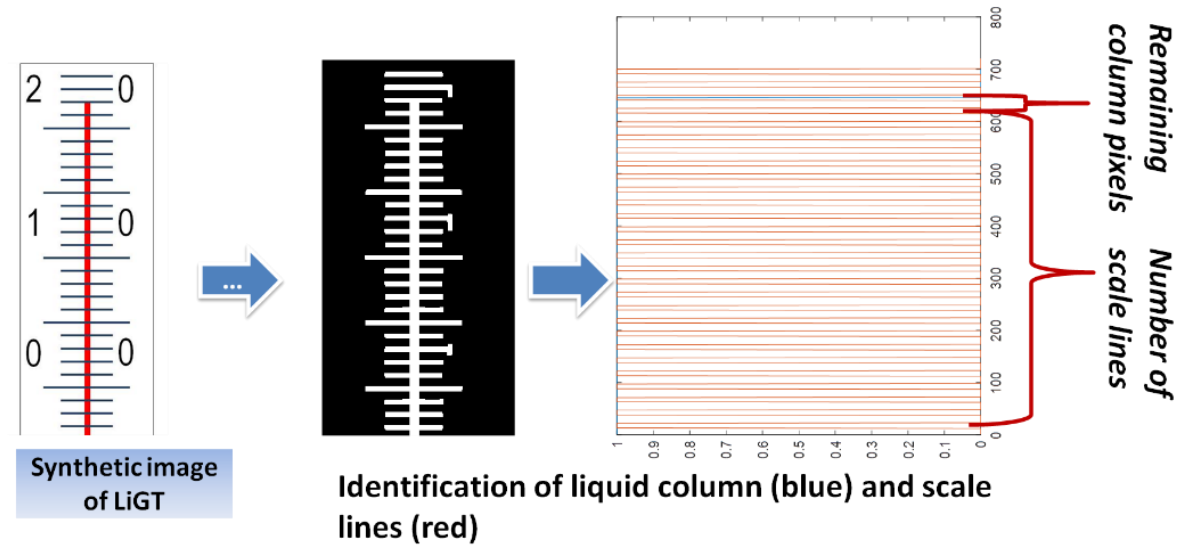

FIGURE 5. The process of identifying the liquid column and the scale line on the LiGT based on the binary image.

The pixel value per scale division (ppt) is calculated based on the ROI (region of interest) in the scale area where the top position of the liquid column is identified. The correction factor which comes from the scale line width is included in equation (1) because the temperature value written on the glass rod is a representation of the center on the scale line width, not the edge. Beside of the underscale line value and the scale division which are the LiGT identity, the ppt value, the number of scale lines, the remaining column pixels, and the scale line width correction are calculated using an developed algorithm in image processing method in this 
study. Based on the processed synthetic image, the following LiGT temperature reading is obtained.

Temperature of LiGT $=-3^{\circ} \mathrm{C}+\left(24 \times 1^{\circ} \mathrm{C}\right)+0.0385 \times(30-5)^{\circ} \mathrm{C}=21.96^{\circ} \mathrm{C}$

By the limitation of reading LiGT with the naked eye, the synthetic image in this simulation is read at $22^{\circ} \mathrm{C}$, a difference of $0.04^{\circ} \mathrm{C}$ with the reading using the developed method $\left(21.96^{\circ} \mathrm{C}\right)$. The difference probably comes from the uncertainty of the top position of the liquid column that coincides with its scale line, which is about 4 pixels wide (equivalent to $0.16^{\circ} \mathrm{C}$ ).

\subsection{EKSPERIMENT RESULT}

After being performed on a synthetic image, the developed method is then tested using a real LiGT image generated from the digital camera. In this study, 3 (three) different LiGT samples were used to test the robustness of the performance of this method. These three LiGT samples have the same scale unit, which is $1^{\circ} \mathrm{C}$. However, the image quality characteristics of them vary on the sides of the column or scale line. The LiGT-1 image in FIGURE 6 shows the quality of the scale line object is very good, but in the case of the column line object at a value between $6^{\circ} \mathrm{C}$ and $8^{\circ} \mathrm{C}$, there is a column line discontinuity. This is clearly seen in the grayscale image segmentation results. On the other hand, in the LiGT-2 image, as shown in FIGURE 7 , the column line object is very good, but the scale line object is not well (looks thin and unclear). The quality of the column line and scale line objects in the LiGT-3 image (FIGURE 8) is not clearer than LiGT-1 and LiGT-2.

FIGURE 6, FIGURE 7, and FIGURE 8 show the results of the real image processing of the three LiGT samples, respectively. Based on these figures, the segmentation process in this method has succeeded in identifying the liquid column line and scale line in the processed LiGT image. Morphological techniques (closing and dilation) have also succeeded in improving the poor segmentation results due to unclear segments of the column or scale object (looks thin). The results of LiGT calculations using equation (1) can obtain the reading result that matches the LiGT temperature value, which also increases the accuracy of the reading.

a. LiGT-1

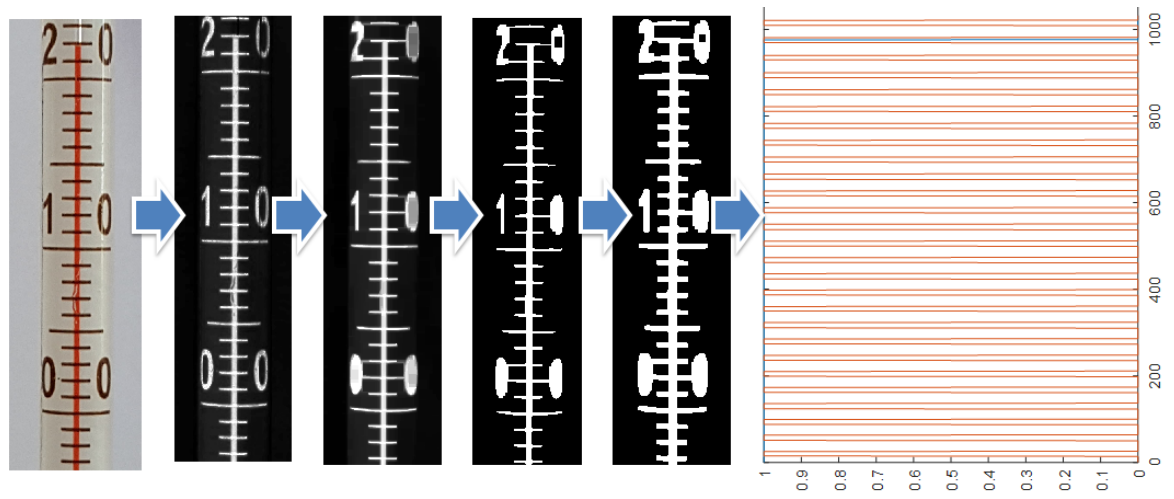

FIGURE 6. Image processing of automatic reading on sample LiGT-1

Temperature of LiGT-1 $=-3^{\circ} \mathrm{C}+\left(25 \times 1{ }^{\circ} \mathrm{C}\right)+0.03 \times(7-7)^{\circ} \mathrm{C}=22.00^{\circ} \mathrm{C}$ 


\section{b. LiGT-2}
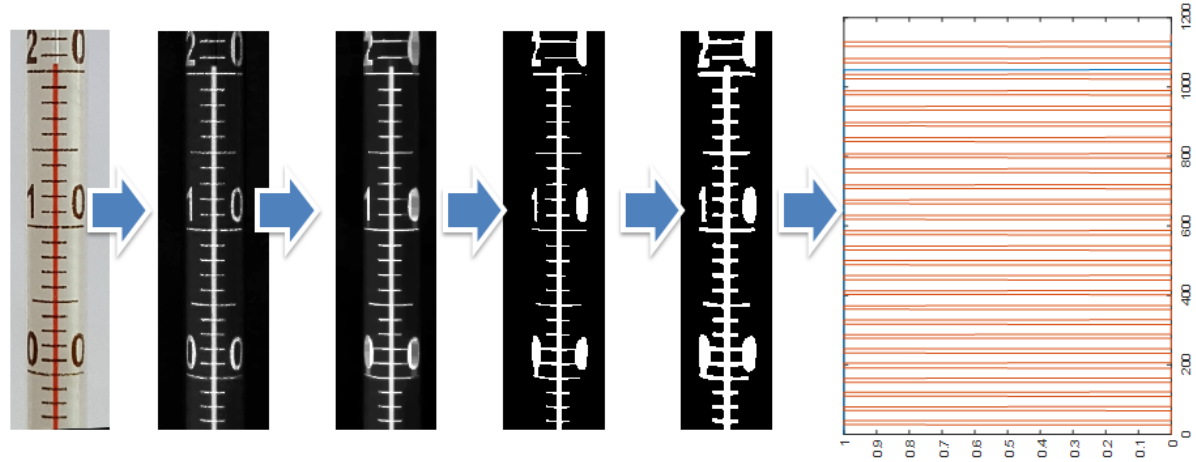

FIGURE 7. Image processing of automatic reading on sample LiGT-2

$$
\begin{gathered}
\text { Temperature of LiGT- } 2=-3^{\circ} \mathrm{C}+\left(23 \times 1{ }^{\circ} \mathrm{C}\right)+0.0217 \times(26-8)^{\circ} \mathrm{C} \\
=20.39{ }^{\circ} \mathrm{C}
\end{gathered}
$$

\section{c. LiGT-3}
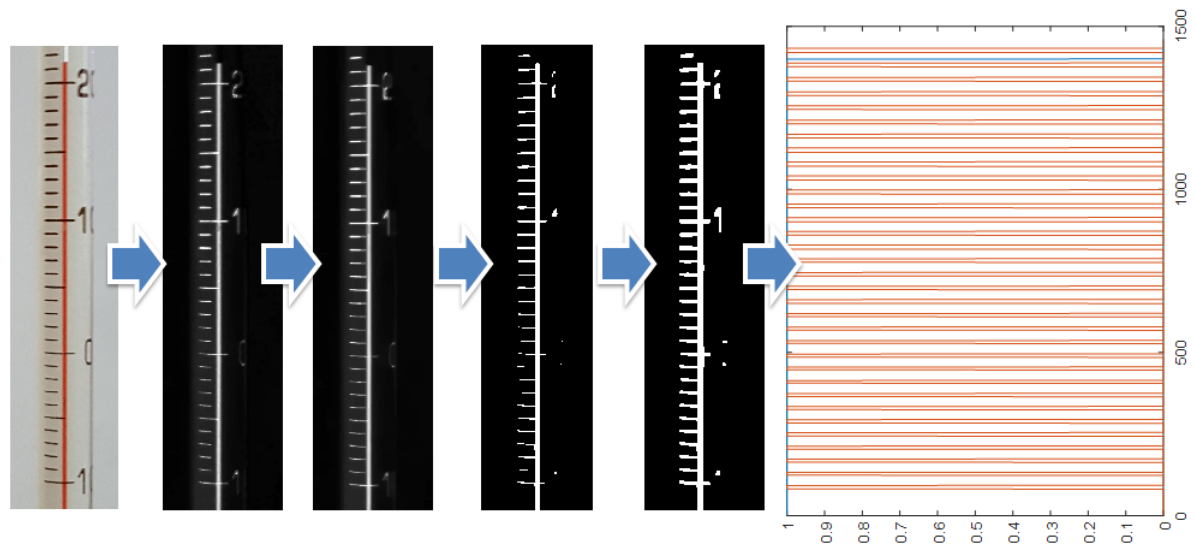

FIGURE 8. Image processing of automatic reading on sample LiGT-3

$$
\begin{gathered}
\text { Temperature of LiGT-3 }=-10^{\circ} \mathrm{C}+\left(31 \times 1{ }^{\circ} \mathrm{C}\right)+0.0227 \times(24-7)^{\circ} \mathrm{C} \\
=21.39{ }^{\circ} \mathrm{C}
\end{gathered}
$$

\section{CONCLUSION}

In this research, image processing and analysis methods have been developed for scale line reading on an analog temperature measuring instrument, LiGT. Through a simulation using a synthetic image, it is shown that the developed technique has succeeded in reading the temperature value of LiGT (which has a $1{ }^{\circ} \mathrm{C}$ scale unit) with a measurement error of $0.04^{\circ} \mathrm{C}$. This deviation probably comes from the uncertainty of the top position of the liquid column coinciding with the scale line. Then in the experimental results using some real LiGT images, it was found that the developed method can be applied to the real images (three different LiGT samples). The used morphological techniques (closing and dilation) in this method effectively improve the reliability of the LiGT reading performance. This technique can improve the poor segmentation results due to an unclear segment of the column or scale line object (looks thin) on the old LiGT. 


\section{REFERENCES}

[1] Jacquelyn Wise, "NIST Measurement Services: Liquid In Glass Thermometer Calibration Service," 1988.

[2] ORGANiSATION INTERNATIONALE DE MÉtROLOGIE LÉGALE, "Recommendation OIML R 133: Liquid In Glass Thermometer," vol. 2002, 2002.

[3] C. William, Dunn, "Fundamentals of Industrial Instrumentation and Process Control," New York: McGraw Hill, 2018.

[4] I. Pu et al., "Methods of Reading Liquid-in-Glass Thermometers," vol. 68, no. 4, pp. 225-230, 2001.

[5] V. Batagelj, J. Bojkovski, and I. Pušnik, "Reading of Thermometers using a Video Camera," 2000.

[6] B. Herlambang, D. Larasati, and A. Prihartono, "Peningkatan Kemampuan Sistem Kalibrasi Termometer," pp. 34-43, 2018.

[7] X. Yi et al., "Reading Identification Algorithms of Mercury Thermometer Based on Machine Vision," pp. 232-235, 2009.

[8] J. C. P. Cheung et al., "An Automated Thermometer Calibration System Imaging Technology: An Automated Thermometer Calibration System Using Optical Character Recognition and Video Imaging Technology," vol. 5775, May 2016.

[9] Roy Davies, “Computer Vision,” 2017.

[10] C. Learning, A. R. Reserved, and C. Learning, "Image Processing," Analysis, and Machine Vision, 2015.

[11] R. Hassan, R. R. Ema, and T. Islam, "Color Image Segmentation using Automated," vol. 17, no. 2, 2017.

[12] P. Widodo, G. D. Haryadi, and A. Widodo, "Induction Motor Centrifugal Blower Health Diagnostic Based on Color Segmentation of Thermal Image and Vibration Signal Feature," vol. 2002, pp. 1-6, 2018.

[13] J. Wang et al., "Quantitative Analysis on Mathematical Morphology," 2018 12th IEEE Int. Conf. Anti-counterfeiting, Secur. Identif, no. 4, pp. 103-106, 2018.

[14] Y. Wu, X. Peng, and K. Ruan, "Improved image segmentation method based on morphological reconstruction," Multimed. Tools Appl, 2015. 